\title{
Banking on social capital: towards social connectedness in distributed engineering design teams
}

\author{
Andreas Larsson, Division of Functional Product Development, Luleå \\ University of Technology, 97187 Luleå, Sweden
}

The idea of an engineering design team as a closely knit, physically co-located community is dissolving as companies become increasingly geographically dispersed. Engineers work together with more people than ever before, but often with very limited knowledge of who they are actually working with, what their collaborators know, and to what extent they can be trusted. Engineering design is a domain where good decision-making is absolutely critical, and building social capital is particularly significant since engineers deal with inherently ambiguous requirements and problems. The fieldwork presented below suggests that 'Know-Who' is a key dimension of expertise sharing in distributed collaborative engineering.

(C) 2007 Elsevier Ltd. All rights reserved.

Keywords: collaborative design, distributed design, engineering design, teamwork, know-who

\section{Corresponding author:}

A. Larsson

Andreas.C.Larsson@ ltu.se
$\mathrm{T}$ his paper addresses the pressing need for companies working with product development to improve how their engineering design teams communicate across locations, time zones, and corporate boundaries. In a highly competitive business environment, costs and lead times are often reduced by extensive outsourcing, through which resources are dispersed cross-continent for the company to obtain the best value for money. Business mergers and acquisitions are increasingly followed by geographical diversity, and when considering the benefits of sharing product and technology platforms with global partners, there are apparent incentives to facilitate and further advance the collaborative work activities of engineering design teams that partake in both national and international development programs scattered across multiple sites.

The paper aims to illustrate why the notion of social capital is particularly appealing to companies working with distributed engineering design teams, where personal connections among distant team members are difficult to build and sustain.

'Social capital consists of the stock of active connections among people: the trust, mutual understanding, and shared values and behaviors that bind the

www.elsevier.com/locate/destud

0142-694X \$ - see front matter Design Studies 28 (2007) 605-622 doi:10.1016/j.destud.2007.06.001

(C) 2007 Elsevier Ltd. All rights reserved. Printed in Great Britain 
members of human networks and communities and make cooperative action possible' (Cohen and Prusak, 2001, p. 4).

Briefly stated, social capital is a side effect of social interaction. It is a fundamental resource for value-creation, since productive communication patterns and trust between team members is crucial for their ability to create a shared understanding and for their willingness and motivation to share information, knowledge, and expertise. In engineering, social capital is particularly important since engineers fundamentally deal with ambiguous requirements and problems, which means that trust in people and expertise is essential to successful decision-making. Viewing engineering design as a domain where good decision-making is critical, this paper builds on the argument that rich social capital has a positive influence on decision-making, while poor social capital has the opposite effect. By using examples from an ethnographic study of day-to-day collaboration in the automotive industry, this paper will report on how the engineers rely on social relationships to carry out their work; to find out 'who knows', to figure out 'who to trust', to negotiate shared understandings, and to bridge gaps between different domains of expertise. The paper will show in detail that these engineering designers depend heavily on their social capital to perform their work well, and it will discuss why improving 'social connectedness' between members of a distributed design team could be a key to better design team performance.

\section{Background: the case for social capital}

The notion of social capital is probably most well-known in the form of Putnam's (2000) historical analysis of America's declining social capital, where he argues that the considerable decline in civic engagement over the last decades is highly related to a simultaneous decline in social connectedness. Civic engagement can, for example, be measured in terms of voting turnout, trust in government and membership in voluntary organizations. Putnam, however, uses bowling as a primary example and observes that although the total number of bowlers in America actually increased by ten percent in a thirteen year period, the bowlers participating in leagues had declined by 40 percent in the same period. So, even though people were bowling more, Putnam noted that they were increasingly 'bowling alone'. Despite being a concept primarily used within the disciplines of economics, sociology and political science, social capital is now finding its way into engineering design and product development. The main reason why product development organizations would want to know more about what social capital is about and how to build it is that they are currently experiencing a trend that has interesting similarities to Putnam's analysis of bowling. Engineering designers, and others working with product development, are continuously expanding the number of teams and projects they are participating in, and they are working in a global context to a far larger extent than only ten years back. Ultimately, engineers are faced with a situation where they are working together with more people than ever before, but often with very limited knowledge of who they are actually working 
with, what their collaborators know, and to what extent they can be trusted. The idea of an engineering design team as a closely knit, physically co-located community is rapidly dissolving as companies are realising the Virtual Enterprise vision, where product development projects essentially require resources that are not easily found within a single company; hence, the sharing of resources, technologies and risks among companies becomes necessary. This perspective involves an organizational flexibility that allows an enterprise to quickly establish the needed relationships to address certain customer needs. This ongoing transformation of industrial organizations, from traditional 'in-house' development with supply chain networks to agile development in Virtual Enterprises implies a strong need to more successfully manage teamwork in temporary alliances - where networks of independent companies, including suppliers, customers and even competitors are '...linked by information technology to share skills, costs, and access to one another's markets. It will have neither central office nor organization chart. It will have no hierarchy, no vertical integration' (Byrne, 1993).

\subsection{The illusion of communication}

Distributed engineering design teams are unmistakably communicating through technology, computers and an ever-increasing variety of information systems, but even though communication happens, there are many doubts about whether or not they communicate the 'right' information, to the 'right' person, at the 'right' time. Moreover, it is important to recognise that just because a message has been sent it does not automatically mean that it has been correctly understood at the receiving end (Clark and Brennan, 1991). This 'illusion of communication' was commented upon by Alan Mulally, the director of engineering for Boeing's 777 project, who noted that we often make the mistake of assuming that others understand things as we understand them, and that just because something has been spoken, it has also been understood. Mulally stated that '...it's the interaction that will allow everybody to come to a fundamental understanding' (Sabbagh, 1996). Similarly, research on software engineering teams at Blekinge Institute of Technology has implied that, in some circumstances, you need to understand the persons 'behind' documents in order to really understand the meaning and importance of the documentation.

We should be clear that the point is not to assert that the technologymediated information exchange is a useless endeavor, for without information there would not be much to discuss in the first place. Rather, it is to suggest, along with Cohen and Prusak (2001) that effective information exchange in itself is not likely to solve the communication problems that distributed organizations face. We need complementary approaches, and we need to acknowledge that '...the problem is not just too much information, but information driving out social talk, or conversation' (Cohen and Prusak, 2001, p. 106). 
Based on his experience as a coach for global student projects between Stanford University and companies and universities across the US and Europe (including Luleå), Van der Loos (2005) commented on the currently flawed perception of distant partners and the work they do, which might be a consequence of a too strong focus on the process, the project, and the product while often forgetting that there are people who are supposed to negotiate a shared understanding of these concepts.

'Current distributed teams communicate by using what amounts to night-vision goggles into the worlds of the distance partner: total tunnel vision, fragmented in time, highly focused on the design project, not the design partners' (Van der Loos, 2005).

Attaching greater significance to the relations and interactions between people resonates well with the notion of Communities of Practice, which is defined by Wenger et al (2002) as '...groups of people who share a concern, a set of problems, or a passion about a topic, and who deepen their knowledge and expertise in this area by interacting on an ongoing basis'.

This definition leads us to draw a distinction between communication and community, because even though distributed design teams essentially share a number of concerns or problems, they have for the most part not achieved enough shared understanding or trust to actually function as a true distributed community of practice when addressing these concerns. Fundamentally, there is not enough mutual awareness to support the articulation work (Schmidt and Bannon, 1992) of distributed teams, which involves the ways in which team members continuously monitor each other's activities to determine how they need to adjust their own activities to mesh well with the unfolding work of their colleagues (Schmidt and Simone, 2000).

\subsection{Social connectedness: from know-how to know-who}

There are numerous different typologies and classifications that are intended to shed some light on what knowledge 'is' and how it can be created and shared. For example, Polanyi (1966) uses the concepts of explicit and tacit knowledge to make a distinction between knowledge that easily can be described in documents and knowledge that we cannot articulate or codify but still are able to express in action. Similarly, Ryle (1984) observes a distinction between know-what (i.e. facts) and know-how (i.e. skills), where the latter concept can be seen as '...the particular ability to put know-what into practice' (Brown and Duguid, 2000, p. 91). To more clearly frame the notion of social capital as a key to successful collaboration in globally distributed teams, I would also like to paraphrase the categorisation of knowledge provided by Quinn et al (1996):

- Cognitive knowledge (Know-What): The basic mastery of a discipline that can be achieved through extensive training and certification. 
- Advanced skills (Know-How): The ability to apply the rules of a discipline to complex real-world problems.

- Systems understanding (Know-Why): The deep knowledge of the web of cause-and-effect relationships underlying a discipline.

- Self-motivated creativity (Care-Why): The will, motivation, and adaptability for success.

Although applicable in both a group and an organizational context, these four dimensions are mostly associated with personal qualities. An underlying principle of social capital is that it does not deal with properties of individuals; it deals instead very closely with the connections among these individuals. As such, it takes interest in the mutuality of social interactions and it implies that although individuals might possess the personal qualities outlined above, this does not directly result in a rich social capital - much since these individuals may have very different possibilities to mobilise the appropriate social networks (Putnam, 2000). Since it probably is acceptable to argue that nobody can know everything, it seems only reasonable that people rely on other people in order to gain the knowledge they are in need of. 'Knowing how' to do something and 'knowing who knows' thus depends heavily on social interaction between people, but in the era of Virtual Enterprises this poses a serious challenge since the ease of connecting to and asking other people depends on the social, geographical and temporal distribution of knowledge (Randall et al., 1996).

In the words of Cohen and Prusak, the notion of social capital suggests '...appropriate organizational investments - namely, giving people space and time to connect, demonstrating trust, effectively communicating aims and beliefs, and offering equitable opportunities and rewards that invite genuine participation, not mere presence' (Cohen and Prusak, 2001, p. 4).

Apart from 'knowing who knows' and knowing how to best access these resources there is also a matter of actually trusting the information that these people provide. This is closely related to the 'illusion of communication' described earlier, in the sense that you need to know more about the people 'behind' the information in order to know that you have understood it correctly and that it satisfies your needs. Trust is essential to social capital and the relationships and mutual commitment that underpins social capital would not exist without a reasonable level of trust. (Cohen and Prusak, 2001, p. 29) Anselm Strauss's (1985) citation of an experienced oncologist well exemplifies the importance of knowing the source of information in order to decide the usefulness of the information:

'I think you just learn to know who you can trust. Who overreads, who underreads. I have got $X$ rays all over town, so I've the chance to do it. I know that when Schmidt at Palm Hospital says, 'There's a suspicion of a tumor in this chest,' it doesn't mean much because she, like I, sees tumors everywhere. 
She looks under her bed at night to make sure there's not some cancer there. When Jones at the same institution reads it and says, 'There's a suspicion of a tumor there,' I take it damn seriously because if he thinks it's there, by God it probably is. And you do this all over town. Who do you have confidence in and who none'.

This is an example of 'bias discounting' (Cyert and March, 1963), which basically means that people assess the value of information based on the perceived credibility of the source (Cicourel, 1990). Also, this points to the view of trust as a function of a relationship, rather than a fixed 'quality' that anyone can just discover. For instance, '...we can trust a person to do the job on time, but the same person might not be trusted when it comes to informing other members of the team' (Cohen and Prusak, 2001, p. 31). Another concept that is very relevant to social capital is 'knowledge brokering' (Hargadon, 1998), which is the process of taking ideas and experiences from one context and adapting this knowledge to fit a new context, for example by realising that research results in the area of composite materials could be directly applied to the development of high performance sports equipment. In more general terms, knowledge brokers provide a link between those who are in need of information and those who have that information.

To conclude this section, I would like to introduce a fifth knowledge category that could be added to the four that Quinn et al (1996) provide. This category has emerged from the fieldwork that will be discussed in greater detail below, but I choose to present it in this context to make the link between my work and related research explicit.

- Know-Who: The interpersonal relationships that enable people to 'know who knows', to 'know who to ask' and to 'know who to trust'.

\section{Methods}

A total of four weeks of ethnomethodologically informed ethnography was carried out at two different engineering departments of a major Swedish automotive company. The 'Body Engineering Department' took part in a platform project involving three automotive brands, all from the same automotive group but located in three different European countries. In this collaborative project, the car platform was divided into three sections, where each brand was responsible (i.e. had the 'lead') for one part of the overall structure (i.e. front, middle and rear structures). The 'Powertrain Department' worked in a similar project, where responsibilities were distributed across three brands/countries, but with the common goal of developing an engine that could be successfully shared among brands. Using traditional ethnographic methods, such as observation, contextual inquiry, and videotaping, the study revealed how engineers mobilise their social capital in a wide range of collaborative work activities, more or less formal, while away from their desk. Both co-located and distributed activities were 
observed, ranging from brief hall-way encounters to multi-site conference calls in large meeting rooms equipped with projectors, whiteboards, and computers. The primary reason for choosing an ethnographic approach is that people are not always aware of the knowledge they bring to a particular situation, and sometimes they may not even have a vocabulary to talk about their own expertise (Blomberg et al., 1993). Ethnography is also a powerful approach when it comes to dealing with the axiom of ideal and manifest behavior; what people say and what they do are not always the same. Ideal behavior is what every 'good' member of a community should do, while manifest behavior is what people actually do (Blomberg et al., 1993). When asked to describe their own behavior, people tend to give an account that is closer to the ideal than the manifest, which has much to do with people trying to live up to expectations and telling people what they want to hear. Consequently, the ability to observe and record activities as they occur in everyday work is a critical factor of success in any study of human activity.

\section{Main findings}

When Bragd (2002) performed an ethnographic study of the Volvo XC90 development from a management perspective, she realised that the decisionmaking process in this particular project was anything but explicit. In fact, she ended up with over 400 hours of recorded meetings - without a single (explicit) decision being made.

'In retrospect, it appeared that they more or less relied on 'directions' or 'main leads', 'recommendations', 'streams' or 'tracks' all of which were concluded in discussions, which organised and structured these different relevant matters. The project team looped the issues within the company' (Bragd, 2002, p. 86). Such 'looping' of issues exemplifies a type of collaboration where decisionmaking is a highly exploratory activity, rather than a rational approach to choose between pre-defined alternatives of action. It is more a matter of continuous exploration and discovery, than a matter of selecting the optimal of a given set of alternatives. Many of the problems that engineering designers experience today are ultimately wicked problems (Rittel and Webber, 1973), meaning that there are no definitive solutions to such problems and that you cannot really understand the problem until you have developed a solution. The final, correct, or optimal solution never really emerges, but the problem solving process still has to stop because you are short of time, money or other resources. 'Every car we build is basically a big compromise,' as one of my informants told me. The fieldwork presented below will draw particular attention to the value of social capital in distributed design teams, pointing out that wicked problems call for a social, collaborative sense-making process, including a great deal of 'know-who'. Fundamentally, it will highlight the importance of social connectedness between distributed team members in order to collectively shape directions or solutions that are 'sufficiently agreeable' or 'good enough' - what Simon calls satisficing (Simon, 1969). 
The addition of a fifth knowledge category, know-who, does not imply that this new category is more important than the other four, it merely offers a complementary way of thinking about aspects that influence successful teamwork and decision-making, and it raises the issue of how to adequately support the creation and application of know-who in global engineering design teams. Know-who principally consists of three dimensions:

- Knowledge-of-Practices

- Knowledge-of-Expertise

- Trust-in-Expertise

I will use these three dimensions to provide a selection of examples from the fieldwork material that intend to demonstrate some of the ways in which 'know-who' plays out in everyday engineering design collaboration.

\subsection{Knowledge-of-Practices}

This dimension relates to the observation that work practices may differ substantially between different parts of an organization. There are no universal ways in which 'things are done', and this is, of course, even more evident in a Virtual Enterprise perspective, where an organization could be widely dispersed across continents, time zones, languages, cultures, professions etcetera. Borrowing Bucciarelli's (1994) concept of object worlds, I argue that people in product development organizations are continuously facing the challenge of bridging the many different understandings that people may have of the same object or situation. For example, the same bill-of-materials can be used for different purposes by different groups depending on each group's needs and objectives, such as dealing with a complex part's structure, keeping track of costs, or planning the development of production tools.

People are often working in many different projects simultaneously, and it is becoming increasingly difficult to keep track of the various 'histories' and 'practices' that correspond to each of these projects. In product development carried out by geographically distributed teams, the ability to know about these diverse practices and the ability to understand how these practices affect your own work seems absolutely crucial to successful collaboration. I will use three excerpts from my empirical material to highlight the importance of gaining access to 'histories' of an organization, or at least locating and gaining access to people that can help overcome the lack of knowledge-of-practices inherent in temporal organizations of the Virtual Enterprise kind.

\section{Excerpt A: Knowledge-of-Practices \#1}

The wicked nature of engineering problems means that cause-and-effect relationships are not always found in technical data sheets. Sometimes, engineers will simply reject the 'technical facts' of a situation and instead resort to the knowledge that they might have of those practices that produced the particular 
data set. As the excerpt below shows, such knowledge-of-practices is crucial in situations when technical data are unreliable, or difficult to interpret.

'The gears cannot be put in at random...they shall be put in when it says that they shall be put in...'

This excerpt is taken from a discussion about how to come up with a better risk analysis concerning fuel emissions from an engine. In laboratory testing, they had not been able to repeat a particular problem, and the group discussed the possibility that one of the reasons for this may be that different drivers are driving the cars in the different test situations. Of course, this statement should not be mistaken for the 'truth'. It is simply one of many examples that highlight how engineers are bringing knowledge-of-practices into their decisionmaking process. The engineer making the above statement was very experienced and he had been through enough engine tests to make the judgment that the problem was related to the testing procedure rather than the product itself. This particular engineer basically located the person or persons 'behind' the risk analysis document, and it seems highly unlikely that he would be able to make that judgment without a substantial knowledge of other people's work practices.

\section{Excerpt B: Knowledge-of-Practices \#2}

Knowing about other people's work practices also makes it easier to more rapidly assess information received from those sources. It enables you to more easily detect changed patterns of behavior, which could potentially impact on your own work, and it enables you to quickly decide if you need to take action to effectively manage these changes.

'[They] have acted a bit more weakly than usual. They have some new people there and they trust simulations for verification. In previous projects, they have made decisions based on their own knowledge. Simulations are good, but sometimes you need answers fast. It was smoother before...'

In this excerpt, my informant has just ended a telephone conference with a manufacturing company. Among other things, they discussed which parts that could be considered as completed and ready for manufacturing. The manufacturing company representatives expressed a concern that they were still waiting for some manufacturing simulations, so they did not yet know if they would be able to go ahead with the production as planned. After the meeting, my informant told me that simulations should be a 'receipt' that verifies that it is actually possible to manufacture a certain part. He noted, however, that it should be possible to tell already from the digital design information if production is feasible or not. Based on his knowledge of how 
things have been done in the past, and based on his awareness of the 'new people' and his knowledge of changed simulation practices, he rather easily made sense of the situation. It should, however, be noted that these companies have been working together for decades, so the mutual knowledge of each other's work practices has been developed for many years. In Virtual Enterprise collaboration, this introduces the challenge of developing this kind of knowledge-of-practices more rapidly, since collaborative engineering will most likely become increasingly time and context restrained.

\section{Excerpt C: Knowledge-of-Practices \#3}

One feature of distributed teamwork is that the feedback loops are often much longer than in co-located teamwork, where you can essentially ask people faceto-face as soon as you suspect that a breakdown in communication has occurred. As the excerpt below indicates, knowledge-of-practices enables you to more easily make sense of the situation and act accordingly if such a communicative breakdown should occur.

\begin{tabular}{ll}
\hline Person A [remote]: & 'Where is [the document], can I have a look at it?' \\
Person B [remote]: & 'I have not received the updated version...' \\
Person C [local]: & 'We sent it to [person E], wanted him to distribute it'. \\
Person B [remote]: & 'It has not reached manufacturing for pre-check'. \\
Person C [local]: & '[Person B], you have the material there...can you \\
& $\begin{array}{l}\text { please distribute it?' } \\
\text { Person B [remote]: }\end{array}$ 'Send it to me again, and we will see if we can solve it today....' \\
$\begin{array}{l}\text { Meeting ends, local conversation starts } \\
\text { Person D [local]: }\end{array}$ & 'I think we have to start sending things to [person B] instead...' \\
\hline
\end{tabular}

In closely knit teams, people tend to develop a reasonably good understanding of how other people work; what their priorities are, how well they plan their work, to what extent they can be trusted to pass information on etcetera. In the above situation, two persons in Sweden were discussing with a group of persons situated in Germany. The topic of this meeting was suggested changes to be made before parts can be released to manufacturing. Apart from the apparent issue of document management, the excerpt points to issues related to knowledge-of-practices. My informants knew very well that this was not only a problem of locating the document; it was also a problem of politics. First, they experienced the problem of assuming that just because the material had been sent it had also been received and distributed according to their intention. Second, they realised that people may have all sorts of reasons not to follow a recommendation, or to do as they are asked. As a consequence of people coming from different object worlds, these people have different objectives and motivations. In this case, the informants knew 'Person E' very well, which enabled them to both make sense of 'E's actions (or non-actions) and to devise a plan that would help them work around this problem. 


\subsection{Knowledge-of-Expertise}

This dimension concerns the social distribution of expertise (Randall et al., 1996), basically meaning that although individual engineers are highly knowledgeable and possess various skills, they still need to rely on other people's expertise in order to really know how or why to do something. The complexity of Virtual Enterprises demands cross-functional collaboration, and global teamwork, in general, leads to a greater diversity in knowledge and skills. It thus becomes increasingly important to be able to locate people with credibility; basically 'knowing who knows' or 'knowing who to ask'.

In co-located teams, knowledge-of-expertise is usually built up naturally and quickly. Through their interactions with others, people gradually learn about the strengths and weaknesses of their colleagues, and when faced with a problem they often have a very good idea of whom to approach for help. Ackerman et al. (2003) note that locating and sharing expertise is a key issue for organizations and that they could move beyond traditional Knowledge Management by also taking interest in the self-organized (e.g. social) activities of employees.

Having knowledge-of-expertise fundamentally means that individuals and groups are aware of the expertise available within their organization, although it may be socially distributed. In the case of HP, the problem of social distribution of expertise has been captured in the phrase 'If only HP knew what HP knows' (Sieloff, 1999), which symbolises the challenge of supporting global sharing of local knowledge. The excerpts below are intended as examples of situations that point to the importance of knowledge-of-expertise.

\section{Excerpt D: Knowledge-of-Expertise \#1}

When it comes to the social distribution of expertise, the problem is not that the required knowledge is missing entirely from an organizational perspective. The knowledge is available within the distributed organization, but it is unfortunately located out of reach for the persons that need it. To bridge such 'islands of knowledge', organizations need people that can connect previously isolated networks of people to each other, such as exemplified in the abstract below.

'My role is to make sure that they have the resources they need...getting people to talk to each other. If I don't know, I'll just ask someone, but many don't work that way...they must dare to go out and ask...they have the competency, but they lack information... they often need information, so I book meetings for them'.

When discussing the issue of team leadership with one of my informants, he reported that one of his most important responsibilities was getting people to talk to each other. His opinion was that the projects were so complex 
that it was absolutely critical to seek additional resources for expertise. He also commented that there are so many e-mails and documents going around so it was often much easier to ask people directly, rather than trying to make sense of written material. Furthermore, since some of his team members were involved in up to twenty different projects simultaneously, he observed that they have difficulties managing information since it was posted in so many different information systems.

My observations of this person clearly confirm his role as a 'knowledge broker' (Hargadon, 1998), who took every chance to point his colleagues in the direction of someone who he felt could help them in their work. His social network seemed far greater than that of most of his colleagues, and he was very skilled in making connections between individuals and groups that previously seemed to be very remotely associated.

\section{Excerpt E: Knowledge-of-Expertise \#2}

By knowing the person 'behind' the information, you essentially add value to that information and you no longer make an assessment based on the information alone - you make an assessment based on both the information in itself and the source of that information. The excerpt below highlights how knowledge of a colleague's previous behavior can indicate what results to expect in the future.

'I'm not really that worried...he's always very skeptical...it sounds much worse than it is. It's just a way of saying that he doesn't like it, but he always meets the requirements'.

In this situation, I was talking to one of my informants directly after a meeting in which he and a colleague had performed a review of the current cost situation (i.e. cost-walk) for a certain part of the car structure. The colleague had not been very pleased by getting the directive to reduce the cost for a particular component, and he expressed his concerns about the anticipated difficulties of achieving the required functionality with less money. However, my informant did not at all seem worried about this. He knew from experience that his colleague often protested rather loudly if demands changed, but since he also knew that the end result was constantly of a very high standard, he expected a similar result this time around too.

The ability to tell what people typically do in various situations is useful because it means that you do not have to accept every piece of information at 'face value'. Recognising patterns of behavior in the workplace enables people to make more informed decisions about the usefulness of information. The above example basically shows the concept of 'bias discount' (Cyert and March, 1963) in action since my informant values the statement from his 
colleague based on his experiences from similar situations in previous collaboration. In essence, he knew the person 'behind' the information.

\section{Excerpt F: Knowledge-of-Expertise \#3}

The excerpt below is taken from a co-located review meeting concerning the status of a number of actions that the team needed to finish in order to clear an upcoming stage gate. The green/yellow/red status is part of a product quality planning process and it communicates the progress towards the successful completion of actions by a certain date. Fundamentally, 'red' status means that there is a high risk that target dates will not be met, or that sufficient quality will not be achieved for the deliverables. 'Yellow' status means moderate risk and that a recovery work plan has been developed, and 'green' status means that target dates and deliverables are on track and meeting objectives.

The status of these actions was supposed to be put into a web-enabled review system, but this particular team did not seem entirely comfortable with the system. To put it briefly; they did not really know how they were expected to fill out the report. In an attempt to deal with their uncertainty of how to use the system, they had invited a person who was a very experienced user of the review software.

'What kind of evidence do we need to put here? If we have three to five percent that is not ready, is that yellow?...would this be green complete?'

Throughout the review, the 'expert user' described his interpretation of how the report should be filled out. It quickly became obvious that a single, 'correct' way to fill it out did not exist. He continuously pointed out that the most important thing to remember was to explain why a certain choice had been made. If a particular action was not applicable, they should basically choose the option 'N/A' and then write a comment or upload a file with 'evidence'. In response to the above questions from a team member, the expert responded that he, personally, would say that the particular action was 'green complete' (i.e. completely finished). He pointed out to the group that they, themselves, knew the most about their own work, and that it was actually a rather straightforward process to use the system; it was really just a way for the team to describe the rationale behind their decisions and their expectations of future results.

This example shows how the team constructs the status of 'green complete'. There simply is no 'right' way to fill out the report; what counts is how the team agrees to view and report their progress. This is in line with Bucciarelli (1994, p. 163), who observes that the definition of a problem is a social choice', that 'there is no way to establish the solution's validity for all possible conditions of testing or use', and that 'what matters is that participants gain 
and remain in control of what they construe as the problem, working both across and within their respective object worlds'. In turn, this also means that to be able to really understand what this particular group means with 'yellow status', you need to know more about the rationale behind their decision and at least some knowledge about the people whose expertise have influenced that decision.

\subsection{Trust-in-Expertise}

Apart from having knowledge-of-practices and knowledge-of-expertise, as described above, engineers must also be able to trust the information they receive. This trust fundamentally boils down to a trust in capacities and abilities, and they need to make continuous assessments about whether or not they can trust on recommendations, advice etcetera that they get from their colleagues. It should be noted that just because an engineer knows of the practices and expertise of colleagues, this does not automatically mean that this knowledge is applicable and useful in every given situation. As mentioned earlier, people can be trusted in some situations but not in others.

Trust-in-expertise is a highly social phenomenon, and it thus has to be established in the social interactions between people. So, just because an engineer is considered competent it does not mean that this person's advice or recommendations will be followed in each and every situation. The excerpts below are intended to show that even though you have 'located' expertise (i.e. found a competent person to ask); you still have to make up your mind as to whether or not to trust this particular person in this particular situation. For every bias, there is also a bias discount (Cyert and March, 1963).

\section{Excerpt G: Trust-in-Expertise \#1}

'This guy is amazing. He's not supposed to be on these meetings...I guess he does it because it doesn't work. It's his job to make sure that we are green everywhere. He's responsible at the gate if we're red somewhere... and he often knows the details better than anyone...'

In this situation, the conversation is with an informant after a distributed review meeting in which a project manager was very active and basically 'driving' the meeting. As the excerpt tells, he is normally not supposed to be in these meetings since he is situated higher up in the project hierarchy. However, since it is his responsibility to ensure that deadlines and requirements are met, he needed to take on a more active role in this particular project. My informant told me that it is uncommon for managers at that level to participate in this kind of meetings, but he also expressed great appreciation for this particular manager because he 'knows what he's talking about'. In many other meetings of this kind that I attended, it seemed like 
participants quite easily found ways to convince the project leaders that they were on a 'promising path' or that they 'soon' would have solved their problems. In this meeting, however, it was rather obvious that the project manager possessed the level of expertise that was required in order for the other participants to understand that he would not be easily misled by vague information. The team members knew that the manager was very experienced, and they took that into consideration when they tried to give answers to his many questions.

The excerpt draws attention to how much trust-in-expertise depends on how much you know about a person's background and experience. In Virtual Enterprise collaboration, this raises the question of how to find out enough about your collaborators to decide if they are competent and how to find out to what extent they and the information they provide can be trusted.

\section{Excerpt H: Trust-in-Expertise \#2}

'What's behind the green numbers?'

This excerpt is taken from another of the meetings in which the above manager took part. Once again, the meeting concerned a review of the status of problems that needed to be solved in order to pass the stage gate. The engineers presented the progress since their last meeting, and they marked the status with numbers and figures of different color (red, yellow, green) to symbolise how far from completion a certain action was. In this meeting, and others, it seemed like the co-located and the distributed group had a completely different perception of what those different status descriptions actually meant. One of my informants told me that 'they always come up green, and we are red everywhere', while also noting that 'the differences are not really that big, but we are probably more likely to ask for help when we have problems'. He said that it was a difference in 'culture' between them and the remote team in that the other team's concept of 'green status' includes a description of the current problem and then a 'roadmap' that describes how to address the problem. His team reported red or yellow status in such situations, and waited with reporting green status until the problem had actually been solved. As a consequence, he said, 'management sees it as they present solutions, while we present problems'.

In this situation, however, the manager did not see it that way. While my informant's team 'got away' with several red status flags, the remote team got a lot of questions regarding their reasons for reporting green status. In short, even though the team formally reported that they had finished the tasks, the manager did not trust their evidence and documentation enough to take that information at 'face value'. 
'If we do this I know that we're going to succeed...it will work without a hitch...if we don't do this I can't guarantee anything... what I'm saying to you right now is what I know will work...it might work in other ways if people bend backwards, but...'

This excerpt comes from a meeting in which a review was made concerning the need for test objects (components and tools). Teams that are in need of test objects have to provide a brief description of what type of components or tools they need and why they need them, but they also have to provide a good motivation for the number of objects that they request and an assessment of the consequences of not being allowed to order these objects. Fundamentally, they have to provide the rationale for their decisions; the underlying needs that well describe why the test objects needs are what they are. It is a way of visualising the process, so that teams cannot just order objects without good reasons. In this particular situation, an engineer had not provided very much information in the documentation so the persons leading the review asked him to verbally describe the needs that apparently were missing in the documents. They gave him a chance to attach credibility to the needs briefly described in the written test object request, and by providing the above motivation he tried to argue for why they should 'trust' him with the requested test objects.

In the end, trust-in-expertise also comes down to how much you actually know about people and their way of working. In teams with low social connectedness, it is not likely that such knowledge and trust will develop.

\section{Conclusion}

The analysis of the fieldwork material highlighted what seemed to be two particularly important aspects of social capital relating to design collaboration in distributed settings. First, 'knowing who knows' is central to any engineer regardless of location since many design problems and activities require contributions from someone with previous experience, or sometimes feedback from a person who was, for example, actually in charge of the latest update to a particular component or document. Second, 'knowing who to trust' is of great importance given the often unclear and vague nature of design problems, forcing designers to put great trust in a colleague's opinion rather than provable facts. The ambiguity in requirements means that engineers need to trace what something means, and understanding what somebody means essentially involves asking people what they mean.

The empirical material indicates that social capital (i.e. Know-Who) is an essential complement to intellectual capital (i.e. Know-How), in the sense that design is carried out in a social context where each individual designer 
needs to strive for a shared understanding with their colleagues to produce a successful design.

The findings from the study clearly point to the potential for companies engaging in distributed collaboration to leverage from a collective social capital, which appears very difficult to build and maintain in the current mode of distributed collaboration. To sustain social capital, relationships between collaborating designers must transcend the traditional location-based approach where local knowledge (e.g. traction problems on icy Swedish roads), at best, can be shared between co-located team members. In many situations today, local knowledge stays local, while much social capital potential is lost. Considering all the different car parts, components, and assemblies that need to meet functional specifications with respect to cost, time, and quality, it is easy to see that even a 'lone genius', should one exist in the company, would be hard-pressed considering all relevant aspects of the design without access to the opinions and experiences of colleagues. The concept of collective social capital as a resource for innovation seems like an appealing idea to any company that wants to excel in distributed collaboration by globalising local knowledge.

Having identified the importance of social capital in global engineering design teams, it is also crucial to recognise the potential for improvement. Bearing in mind that most current technologies for distributed collaboration do not allow engineers to neither build nor use social capital as effortlessly as in co-located settings, it is absolutely critical to further explore research directions that will propose and evaluate technologies and workspaces that are better tuned to the concept of social capital in distributed design teams.

\section{Acknowledgements}

I am greatly appreciative of the financial support provided by both VINNOVA and the Kempe Foundations. The discussions I have had with Dave Randall, Manchester Metropolitan University, and Liz Carver, BAE Systems, have substantially contributed to the analysis. Finally, I am sincerely grateful to my informants for their time and willingness to participate.

\section{References}

Ackerman, M, Pipek V and Wulf V (eds) (2003) Sharing expertise: beyond knowledge management, MIT Press, Cambridge, MA, USA

Blomberg, J, Giacomi, J, Mosher, A and Swenton-Wall, P (1993) Ethnographic field methods and their relation to design in D Schuler and A Namioka (eds) Participatory design: principles and practices Lawrence Erlbaum, Hillsdale, NJ, USA pp $123-155$

Bragd, A (2002) Knowing management: an ethnographic study of tinkering with a new car, Ph.D. dissertation, School of Economics and Commercial Law, Göteborg University, BAS Publisher

Brown, J S and Duguid, P (2000) The social life of information Harvard Business School Press, Boston, MA, USA 
Bucciarelli, L L (1994) Designing engineers MIT Press, Cambridge, MA, USA Byrne, J (Feb 8, 1993) The virtual corporation Business Week 1993;98-104 Cicourel, A V (1990) The integration of distributed knowledge in collaborative medical diagnosis, in J Galegher, $\mathbf{R} \mathbf{E}$ Kraut and C Egido (eds) Intellectual teamwork: social and technological foundations of cooperative work Lawrence Erlbaum, Hillsdale, NJ, USA pp 221-242

Clark, H H and Brennan, S E (1991) Grounding in communication in $\mathbf{R}$ M Baecker (ed) Readings in groupware and computer-supported cooperative work: assisting human-human collaboration Morgan Kaufmann, San Francisco, CA, USA pp 222-233

Cohen, D and Prusak, L (2001) In good company: how social capital makes organizations work Harvard Business School Press, Boston, MA, USA

Cyert, R M and March, J G (1963) A behavioral theory of the firm Prentice-Hall, Englewood-Cliffs, NJ, USA

Hargadon, A (1998) Firms as knowledge brokers: lessons in pursuing continuous innovation, California Management Review Vol 40 No 3 pp 209-227

Polanyi, M (1966) The tacit dimension Doubleday, Garden City, NY, USA

Putnam, R D (2000) Bowling alone: the collapse and revival of american community Simon \& Schuster, New York, NY, USA

Quinn, J B, Anderson, P and Finkelstein, S (March-April 1996) Managing professional intellect: making the most of the best Harvard Business Review

Randall, D, O'Brien, J, Rouncefield, M and Hughes, J A (1996) Organisational memory and CSCW: supporting the 'Mavis Phenomenon', in Proceedings of $\mathrm{OzCHI}$, Hamilton, New Zealand

Rittel, H and Webber, M (1973) Dilemmas in a general theory of planning Policy Sciences 4 pp 155-169

Ryle, G (1984) The concept of mind University of Chicago Press, Chicago, IL, USA Sabbagh, K (1996) $21^{\text {st }}$ century jet: the making of the Boeing 777 Pan Books, London, UK p 36

Schmidt, K and Bannon, L (1992) Taking CSCW seriously: supporting articulation work Computer Supported Cooperative Work Vol 1 No 1 pp 7-40

Schmidt, K and Simone, C (2000) Mind the gap! Towards a unified view of CSCW, in Proceedings of COOP2000, Fourth International Conference on the Design of Cooperative Systems, INRIA, Sophia Antipolis, France

Sieloff, C G (1999) If HP knew what HP knows: the roots of knowledge management at Hewlett-Packard Journal of Knowledge Management Vol 3 No 1 pp 47-53 Simon, H A (1969) The Sciences of the Artificial (2 ${ }^{\text {nd }}$ edn) MIT Press, Cambridge, MA, USA

Strauss, A L (1985) Social organization of medical work University of Chicago Press, Chicago, IL, USA

Van der Loos, M (2005) Stanford University, Personal e-mail communication, February

Wenger, E, McDermott, R A and Snyder, W (2002) Cultivating communities of practice: a guide to managing knowledge, Harvard Business School Press, Boston, MA, USA p 7 